thought further that the etrain of another four months of pregnancy, increasing, as inevitably it must, during the latter part of the term, would be too much for the weakened heart, and that, therefore, it was justifiable to terminate the pregnancy. If you decide to induce abortion in one of these cases, then the best method is to give an anaesthetic, to dilate the cervix, and to empty the uterus at one sitting. The class of case, then, in which abortion should be induced, is that in which ordinary medicinal treatment has produced no or only very little improvement in the general symptoms, and in which no further improvement in the cardiac condition is likely, so that it is essential that the strain of a long pregnancy should be avoided if possible. The following case is an illustration of the class in which premature labour may be induced. The patient was 25 years of age, a primipara with double aortic disease. She had some oedema of the legs, was markedly anaemic, and had severe syncopal attacks from time to time. With treatment by rest in bed and medicine she improved considerably, but when she got out of bed and about she had further syncopal attacks, so that her condition was not quite satisfactory. We tided her over her difficulties as long as possible, but at the thirty-eighth week I determined to induce labour because the syncopal attacks were still rather frequent, and it was therefore thought best to put an end to the pregnancy. A Champetier de Ribes's bag was introduced under an anaesthetic, and when the first stage was completed the patient was delivered under ether with forceps. The child is alive; the mother did well, and at the present time has lost all her cardiac s. mptoms. Some authors hold that the induction of premature labour increases the danger to the patient; but I do not think that this is so, because if you induce premature labour you can make arrangements to carry out the delivery in the best conditions and with the advantage of skilled assistance. I think, then, that in the case of patients who do not improve under ordinary medicinal treatment, it is wiser to terminate the pregnancy rather than to let the patient go on to full term. This does not agree with the conclusions of Hicks and French based upon the obstetrical histories of their 300 cases. They contend that the induction of premature labour is not necessary, since the great majority of their patients bore a considerable number of children with little or no danger. No doubt that is true of the general run of cases : just as it is true that the majority of cases of valvular heart disease complicated by pregnancy do very well with ordinary medicinal treatment. But you will meet with exceptional cases from time to time which require not only medicinal treatment, but, in order to lessen the strain thrown upon the overburdened heart. require, further than this, the induction of abortion or of premature labour.

\section{Conduct of the Labour.}

The treatment of the condition at the time of the patient's confinement is of some importance. You must guard against the risk of cardiac failure, and if there are signs after the delivery of the child that the right side of the heart is over-distended, you should encourage postpartum haemorrhage, or you should actually bleed the patient. Such a mode of treatment undoubtedly yields good results where there are symptoms of over-distension of the right side of the heart and consequently danger of paralysis. Where the patient is pallid and the pulse very small, with no signs of over-distension on the right side, and where it is probable, therefore, that the blood is accumulating in the abdominal veins, the intra-abdominal pressure should be maintained at the time of delivery by the use of a sandbag or a tight binder, and appropriate means must be taken to stimulate the heart's action.

The Prohibition of Marriage.

There remains now for our consideration only one question, and that is the truth of the dictum laid down in many books, that a patient with heart disease should not marry, or if she does marry she should not have children, or if she does have children she should not suckle them. Such a dictum, you will agree, is - too sweeping. The majority. of women with heart disease pass through their pregnancy and confinement with perfect safety and have no symptoms, and therefore it is not right to say that a young woman who has heart disease should never marry. - If her heart disease is compensated and there are no eymptoms, she may marry. Cardiac failure probably. will occur sooner or later, as Hicks and French point out, whether she becomes pregnant or not. The bad effect produced on the heart by pregnancy is, on the whole, not sufficiently marked to justify you in advising a patient strongly that she should not marry. It is true that if she marries it will be better for her not to have children, and it is true that if she does have a child she should not suckle, but it is not right that a woman with heart disease should be forbidden to marry. Although the danger is undoubted, and the mortality is as high as 12 per cent., yet it has been exaggerated, and the majority of these patients do perfectly well, and run no very great extra risk. So that a young girl with heart disease which is compensated, and which is not complicated by any accompanying disease of the lungs or other viscera, may be permitted to marry. Her heart will probably fail sooner or later, whether she marries nr not, but whether the time of the onset of such failure of the heart will be precipitated by child bearing is a matter which admits of argument. There probably will be some precipitation, but it is doubtfol whether the risk of this is so marked as to justify you is denying her the right to marry.

\section{EFFECTS OF DIET ON THE DEVELOPMENT AND STRUCTURE OF THE UTERUS.}

\section{BY}

MALCỌM CAMPBELL, M.A., M.B., Ch.B., F.R.C.8.Edin., LECTURER IN MIDWIFERY AND GYNAECOLOGY, SCHOOL OF MEDICINE OF THE ROYAL COLLEGES, EDINBURGH.

(From the Physiological Laboratory, Edinburgh University.)

THE alarming and persistent decline in the birth-rate is a matter of national interest the importance of which can hardly be over-estimated. The purely medical aspect of this question is, however, exceeding]y difficult of approach, since social factors and social selfishness have un. doubtedly a material influence. During the last generation, however, there has undoubtedly been a marked change in the relative proportions of the constituents of the average man's diet. Can such a change of diet have any influence on the birth-rate?

The following investigation was undertaken to discover what changes, if any, were produced in the development and structure of the uterus by various diets.

The animals employed in the research were rate. The uteri of 86 animals were examined both macroscopically and microscopically. The tissue for microscopic examination was removed in all cases from, as nearly as possible the same area, the junction of the distal and mid thirds of the uterus.

Eight wild rats, in various stages of development, from the immature to the adult animal, were examined in order to form an opinion as to the structure of the uterus in animals living, presumably, under natural conditions.

The remaining animals were divided into five series, namely :

(a) A series of 13 animals fed, f:om weaning, for periods of from nine to fourteen weeks on an exclusively milk diet. In one section of this series plain milk was used; in another, Pasteorized milk; in the third, therilized milk.

(b) A series of 27 animals fed for periods of from twenty-one days to nine months on bread soaked in milk.

(c) A series of 11 animals fed for periods of from four to fourteen weeks on a rice diet.

(d) A series of 5 animals fed for varying periods on a diet of porridge or oats.

(e) A series of 22 animala fed for periods of from twenty days to eight months on a raw meat diet.

In the cases of the raw meat and rice diets, some animals were put on the ditt as soon as weaned, others after they had reached various stages of development.

The uterus of the adult wild rat is lined by columnar epithelium. There are glands lined by epithelium which varies from low cubical to columnar in type. The mucous coat is bounded externally by a muscular coat. In the mucous layer three varieties of cells are found:

1. A cell with a large round or oval, selatively faintlystaining nucleus. Trs ay $\mathrm{T}$ esrs to be a young connective
tissue type 0 . cell. 
2. A cell with a small, round, darkly-staining nucleus, comparable to a lymphoid cell.

3. $\Delta$ cell with an elongated, very darkly-staining nucleus, similar to cells got in fibrous tissue.

In the wild rat the large cells are most numerous (Fig. 1). In the wild rat the cells of the other types are few in number, and are chiefly found in the part of the mucosa near the muscular coat.

From the examination of this series of 86 animals it is evident that in animals of the same age and approximately of the same weight, living under similar conditions, the uteri may vary within a limited range in size and development. The muscular coat is relatively uniform.

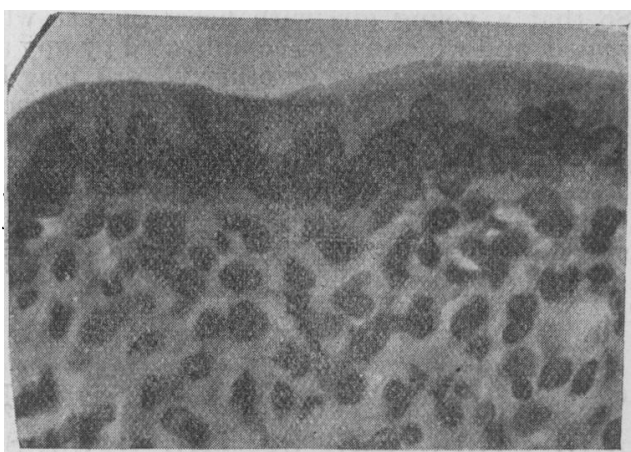

Fig. 1.-Mucosa of adult wild rat, showing predominance of large type of cells $(\times 500)$

The mucosa shows the greatest variations. While in most cases the epithelium lining the cavity is columnar, in some it is cubical; there are also found marked variations as to the position of the nucleus and its staining reactions.

The animals fed on milk and bread soaked in milk approximate most nearly to the type of structure got in the wild rat (Figs. 1 and 2 . In the other groups, fed on what we may term "abnormal diets," namely, rice, porridge, oats or raw meat, there is found a relatively constant departure from the normal. The type of change is common to all abnormal diets; its severity varies.

The severity of the changes induced are found to be in proportion to the ages of the animals at the time when the ahnormal diet was begun. The changes are most marked in the animals put on the diet at weaning; they are less marked the more mature the animal at the time of the commencement of the abnormal diet. In a fullydeveloped animal, any abnormal diet may fail to

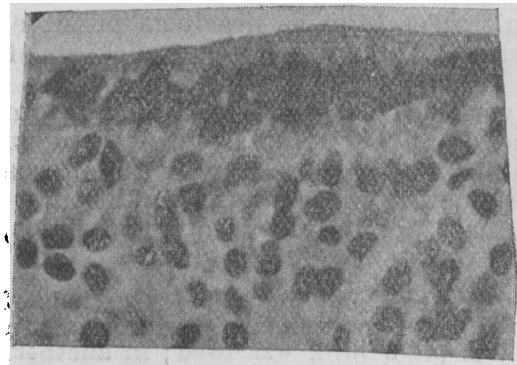

Fig. 2.-Mucosa of adult bread and milk fed rat $(\times 500)$.

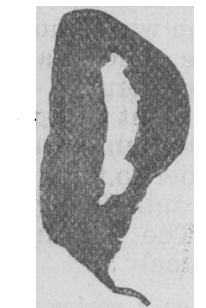

Fig. 3.- Section of uterus of young rat aged 10 weeks, fed ox flesh $(x 20)$, materially change either the size or structure of the uterus.

In regard to the development of the uterus, an abnormal diet appears to arrest the growth of the uterug; compare Figs. 3 and 4, also Figs. 5 and 6 . This arrest of development is most marked in animals fed from weaning on ox tlesh, but is also very well seen in animals fed on rice or on porridge or oats.

In regard to structure, all the abnormal diets led to a diminution of the number of the large connective-tissue type of cells, and a relative increase in the small cells. This change, which may be described as a fibrosis (compare Fig. 7 with Figs. 1 and 2), was most marked in animals fed from weaning on an ox.flesh diet for periods of from four to five months; in this group of animals none became pregnant, while controls, from the same litters, fed on bread and milk, all had young.

From these observations it seems justifiable to state:

1. The use of a non-physiological diet-for example, exclusive flesh, rice, or porridge-induces in the great majority of cases a modification in the structure of the

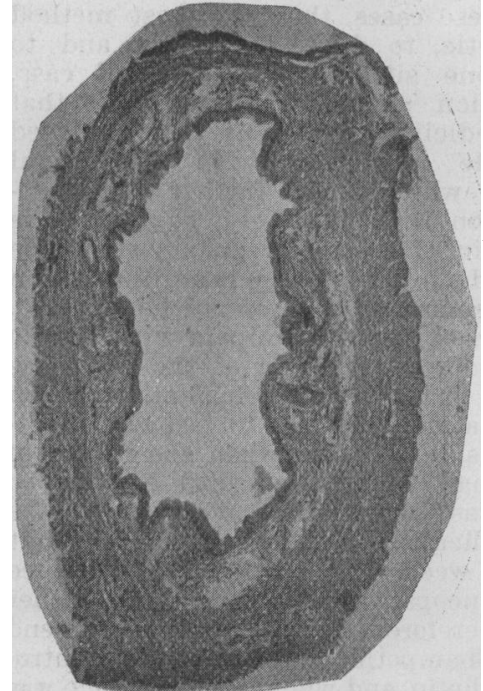

Fig. 4.- Section of uterus of young rat ged 10 weeks, from same litter as Fig. 3 , fed from weaning on bread soaked in

uterine mucous membrane. This modification consists in a diminution in the number of the large connective tissue type of cells, which appear to be important constituents in a physiologically active mucosa.

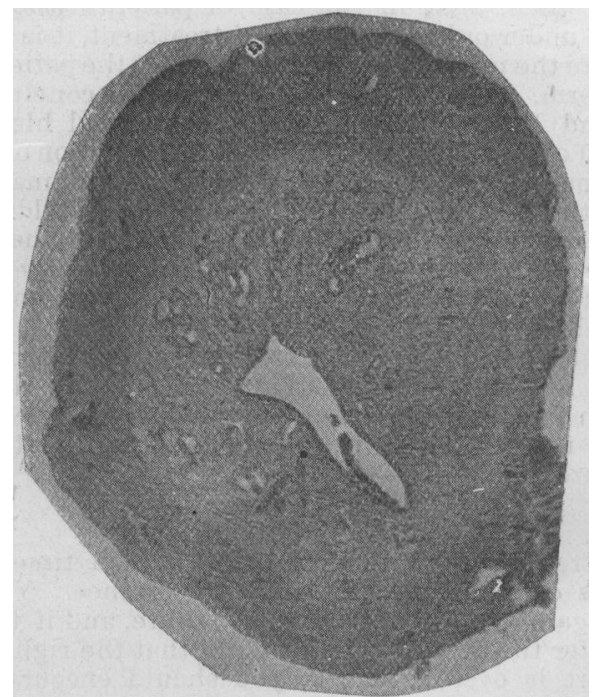

Fig. 6.-Section of uterus of adult rat aged 7 months fed on bread and milk $(\times 20)$.

2. The structural change is most profound in animals ed from weaning on an exclusively ox-flesh diet. In such animals the development of the uterus is also most interfered with.

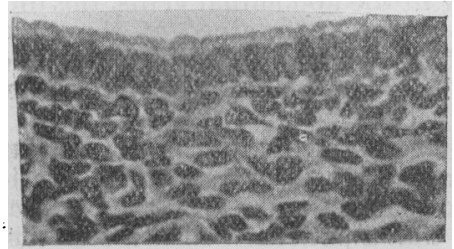

Fig. 7.-Mucosa of adult meat-fed rat, showing marked fibrotic change $(\times 500)$.

3. The structural change in 2 is associated with sterility. Chalmers Watson, to whom I am indebted for much of the material used in this investigation, pointed out ${ }^{2}$ that meat diet, if begun at weaning, almost invariably led to sterility. The present investigation shows "that the 
sterility is probsbly due to the structural and developmental abnormalities in the uterus induced by the abnormal diet. It has been shown ${ }^{2}$ that the consumption of meat per head in this country is to-day almost seventeen times as great as it was in 1850 . During the same period the fall in the birth-rate has been most marked.

While it would be unwarrantable to attempt to found any theories in regard to the falling birth-rate on the results of this limited experiment, yet, when we add to the above facts the further consideration that the diminished birth-rate is most marked in the better-off classes of society-that is, among the very classes whose means permit of an unrestricted use of the more expensive meat diet-it is evident that the food factor is one which is at least worthy of consideration in dealing with the great question of the falling birth-rate.

REFERENCrs.
1 Journal of Physiology, vol. xxxiv. 2 Lancet, July, 1905.

\section{A Case OF SUDDEN DEATH aT THE CLIMACTERIC.*}

BY ELDON PRATT, M.D.LOND., M.R.C.S., HENFIELD, SUSSEX.

ON August 3rd, 1906, I was hastily summoned to see a woman who was said to be in a fit. I was on the spot within a few minutes, reaching the house at 9.10 a.m. I found her lying supine on a sofa dead.

She was a highly-respectable woman, aged 45 years. The history of this fatal attack was as follows: She rose as usual at $5.30 \mathrm{am}$, on the morning of her death, and attended to the requirements of the house taking only a cup of tes with her husband, who left for work at 6 a.m. She was quite cheerful and complained of nothing. Her next door neighbour saw her at 7.20 a.m., and remarked that she looked "faint and rather bad"-lately a not unusual thing with her, as she knew the "change of life" was about her. She said she began to "feel queer" about 7 a.m. Her neighbour gave her some hot te at 7.30 a.m., which was quickly vomited. Smelling salts were administered as she continued to feel faint, and eventually her hnsband was sent for. Although so faint ghe was cheerful, and quite thought she would soon be feeling better ; she retched quite thought she would soon be feeling better; she retched two or three times but brought nothing ap after the first vomit.
At 8.45 a.m. she seemed to change suddenly; the hands became clenched, the face somewhat dusky, and the nails discoloured ; she said she felt very cold and she looked as if a "fit" were impending. A few minutes later, and quite suddenly she changed again for the worse, became unconscions gave three blowing expirations, and then seemed ras dead When questioned as to why I was not sent for sooner, the neighbour said she had seen her in many previous attacks quite as bad.as, or even worse than, this one, except for the quite as bad as, or even worse than, this

The recent history of this woman was thus: For the last year she had suffered from occasional severe headache; for the last six months she had been subject to "fainting turns," with frequent retching, such attacks lasting half an hour to an hour, when she would be all right again : the attacks always occurred early in the moming. The frequent flushes and cold sweats of the climacteric were experienced, and irregular catamenia, of late every two weeks or so, not much loss, but extending over a longer period than normally. The last extending over a longer period than normally. The last was a healthy, cheerful, bright, and happy woman. She had borne seven children, five now living. Her father died suddenly at the age of 60 .

The autopsy revealed nothing, all organs and structures being normal, with no signs of internal haemorrhage or of poisoning.

The following points are especially worthy of note: (1) The fatal attack occurred during the climacteric ; (2) attacks of a similar nature (except for the fatal termination) had occurred before; (3) the attacks were always in the morning; and (4) absence of any signs of disease post mortem.

It is a well-known fact that the nervous organization of most women is put to a considerable strain during the climacteric, and attacks similar to the one recounted above are common enough, being reflex in origin, and always occurring early in the morning, in which respect the attacks are analogous to the vomiting of pregnancy. Whereas the symptoms associated with the climacteric are not usually of a serious character, I take it as quite within the bounds of possibility for an attack such as I have described, and originating in the genital organs, to so : act *A Abstract of a paper read before the Medico-Legal Society, March 12th, 1907 . reftexly that the balance would turn towards death instead of towards recovery. For have we not in this case the evidence of the neighbour who said that she had seen the deceased in attacks worse than this last fatal one, except for the immediate change at the end? Yet from these sufficiently serious attacks she had always previously recovered. Be it noted that this change at the end of the attack was a matter of a few seconds-it was truly a case of sudden death. The negative result of the autopsy alse supports me in this solution of the cause of death. In my evidence at the inquest $I$ gave as the cause of death "asthenic syncope immediately dependent upon the climacteric." Such a cause of death, although rare, seemed to me to be so obvious that subsequently I was indeed surprised to find no record whatever of any similar case; after searching numerous authorities, I have failed entirely to discover that the climacteric has been held to account for sudden death; hence my paper with a view to ascertaining the opinion of others.

\section{A NOTE ON THE USE OF THE BLUNT HOOK.} Bx J. EDWARD GODSON, M.B., B.Сн.BIRM.

THE point I desire chiefly to emphasize in the following report is the comparative ease with which delivery was effected with the blunt hook in a case which presented elements of great difficulty. As a matter of fact, I doubt if any other means could have been successfully employed without recourse to anaesthesia, and this, too, where the use of chloroform was practically inhibited.

Mrs. G., an 8-para, with advanced mitral disease, commenced labour on April 4th, 1907, and after several pains the membranes ruptured and the waters escaped in one gush. The pains then abated, but continued at intervals of about an hour. Her last two confinements had been prolonged and severe; the sixth a shoulder presentation, the seventh a vertex terminated by high forceps extraction. In her case there were several causes high forceps extraction. In her case there were several causes debility, uterine inertia, swelling and oedema of the soft parts, debility, uterine inertia, swelling and oedema of the soft parts, and above all marked contraction of the A.P. diameter
brim produced by projection of the sacral promontory.

I was called to see her on April 5th, and found the os uteri the size of a sixpence, the soft parts very oedematous and a breech presentation (abdomino-anterior position) with the legs fully extended on the trunk. As labour was progressing naturally, I judged it unwise to interfere at this stage, and contented myself with watching her closely during the next forty-eight hours. The general condition continued good the uterine pains were hesitating, long-delayed, and inadequate,
the dilatation of the os was progressive but tardy, and there the dilatation of the os was progressive but tardy, and there was a free escape of meconium. On April 7th the patient was in much the same condition, but suffering from want of sleep and inability to take nourishment, while the uterine contractions still came at half-hourly to hourly intervals, and the oedematous os would now admit the tips of four fingers. After some hesitation I determined to leave her yet awhile, being chiefly infuenced by the long-interval character of the peing the desirability of further modelling and descent of the breech, the danger of chloroform with the heart so faulty, and the difficulty of working without it in so confined a space, and with the presentation so high up. The rectum was emptied by enema, the vagina washed out with antise ptic douches, four 5-grain doses of quinine were given every four hours to whip the uterus into quicker action, and liquid food was administered regularly. Under this treatment the pains became more frequent, and the os was fully dilated by 10 p.m., but to counteract these advantages the patient had an alarming attack of spncope, and the breech became impacted. I tried to break of the presentation and bring down a leg, but found this even more impossible now than it had been at an earlier stage. An more impossible now than it had been at an earlier stage. An attempt to get a fillet over the thigh was equally unsuccessful ;
while the forceps were easy to apply and equally easy to withdraw, as they failed to obtain an efficient grip.

The blunt hook remained as a final resource, the instrument to hand being of an obsolete pattern with an internal diameter of 13 in. A small hook is easier to use than a large one, but possesses certain dangers and disadvantages of its own; the device by which I have attempted to overcome these will be mentioned later on. I applied the instrument without diffimentioned later on. I applied the instrument without difficulty, and extraction of the breech followed with greater readiness than might have been anticipated. The shouldersthe most massive I have ever seen in a newborn child-caused considerable delay, but this did not matter much as the child had evidently been dead for several days
delivery was concluded without trouble.

The child was a male, at full term. It bad an offensive odour, and large surfaces were denuded of epidermis. It was $12 \mathrm{lb}$. in weight and 23 in. long. The bones of the skull were strong and normally ossified: the occipito-frontal circumference was 15 in the occipito-mental diameter was 6 in. while the biparietal was 4.50 in. The circumference of th 